\title{
Cytokines in the Intervertebral Discs of Patients Undergoing Lumbar Discectomy and Fusion for Degenerative Disc Disease
}

\author{
Pasquale X. Montesano ${ }^{1}$, M.D. and *Jason M. Cuéllar, M.D., Ph.D. ${ }^{2}$ \\ ${ }^{1}$ Spine Surgeon, Montesano Spine and Sport, USA \\ ${ }^{2}$ Spine surgeon, Department of Orthopaedic Surgery, Cedars-Sinai Medical Center, USA \\ Submission: December 14, 2016; Published: January 06, 2017 \\ *Corresponding author: Jason M. Cuéllar, M.D., Ph.D. 450 N Roxbury Drive, 3rd floor, Beverly Hills, CA 90210, Tel: 310-385-7766. \\ Email: cuellarspine@gmail.com
}

Abstract

Study Design: Prospective case series.

Objective: Determine whether particular inflammatory cytokines are present within the painful degenerative disc and if so, whether these may serve as biomarkers for post-operative improvement.

Summary of Background Data: Low back and leg pain are common problems that may arise as sequelae of degenerative disc disease of the lumbar spine. The production of pain by the degenerative disc remains controversial and the underlying pathophysiology is largely unknown. Previous studies of cytokines in the disc have predominately focused on in vitro culture of disc tissue after surgical excision. The in vitro culture environment may influence the expression of cytokines thus producing different results than those present in vivo.

Methods: Thirty-one lumbar intervertebral discs from 27 subjects with low back pain were removed using an anterior approach and placed in a solution containing protease inhibitors. Lavage of the disc space was also performed in 19 discs during discectomy for comparative analysis to whole disc samples. For cytokine analysis the solution surrounding each disc and the Inradiscal lavasates were then analyzed for 27 cytokines simultaneously in each sample using a Multiplex immunoflourescent assay system. Cytokine data were also compared to data from 20 non painful lumbar disc samples - 4 from the non painful control level during discography and 16 from intraoperative lavage of non painful scoliosis discs.

Results: In whole discs there was a statistically significant elevation of interleukin (IL)-13, IL-10, IL-9, macrophage inflammatory protein (MIP)-1beta, fibroblast growth factor (FGF)-basic, Eotaxin, vascular endothelial growth factor (VEGF) and interferon-gamma-induced protein-10 (IP-10) compared to non painful control discs. There was also a significantly greater concentration in lavage samples of IL-10, IL-12, IL-9, MIP$1 \mathrm{~b}$ and VEGF compared to non painful control discs. There was no statistically significant difference in the concentration of cytokines measured by whole disc lavage compared to disc space lavage except for IL-10 ( $<<0.001)$, GM-CSF $(p<0.05)$ and IL-12 ( $<<0.005)$; the levels of which were greater in the samples taken from the disc space than from the whole disc. Cytokine concentrations measured in control disc were zero for all measured cytokines except IL-17 and IP-10. No significant correlation was found between pre-op VAS or pre-op ODI and any analytic. There was a significant correlation with pre-op SF-36 and IP-10 ( $<<0.001$; Rho $=.75)$ and IL-9 $(\mathrm{p}<0.05$; Rho=0.61). Weak to moderate correlation was found for 6-month VAS and MCP-1 (Rho = -.48), IL-6 (Rho =0.59), RANTES (Rho =0 .59) and PDGF-bb (Rho = 0.67). Statistically significant but weak to moderate correlations were found between change in VAS from pre-op to last follow-up for MCP-1 ( $<<0.05$; Rho $=0.47)$ and VAS at last follow-up for MCP-1 (Rho $=0.60 ; \mathrm{p}<0.005)$ and GM-CSF $(\mathrm{Rho}=0.47 ; \mathrm{p}<0.05)$.

Conclusion: Out of the 27 cytokines measured using the multiplex panel, there was a significantly greater concentration of IL-13, IL-10, IL-9, MIP-1beta, FGF-basic, eotaxin, VEGF and IP-10 in the intervertebral disc of subjects with degenerative disc disease undergoing surgical treatment with anterior/posterior lumbar fusion compared to non-painful control discs. The pre-op concentration of MCP-1, RANTES, IL-6 and PDGF-bb had the strongest correlation to outcome measures.

Keywords: Spine; Lumbar; Degenerative disc disease; inflammation, inflammatory cytokine; Multiplex; Interleukin; Eotaxin; Interferon gamma induced protein; Vascular endothelial growth factor; Fibroblast growth factor; Macrophage inflammatory protein

\section{Introduction}

Lumbar disc herniation can manifest as sensory abnormalities and/or pain in the affected area of the lower back, buttock and/or lower extremity. Nerve root or dorsal root ganglia compression may be responsible for paresthesia, but may not completely explain the production of pain [1]. Although the literature suggests a correlation between radiculopathic 


\section{Orthopedics and Rheumatology Open Access Journal}

pain and the presence of inflammatory mediators, prior studies have focused on a small number of inflammatory mediators or have been based on in vitro analyses.

Ahn et al. [2] observed an association between IL-8 and TNF-alpha mRNA expression and radicular pain in a study of surgically excised discs from 23 patients with disc herniation [2]. In a study of 72 patients undergoing anterior spinal surgery for sciatica and scoliosis (control), scoliotic and herniated intervertebral disc tissues were obtained intraoperatively, and analyzed for the production of pro-inflammatory IL-8 and monocyte chemo attractant protein-1 (MCP-1). Compared to controls, tissue samples from patients with radiculopathic pain expressed both MCP-1 and interleukin (IL)-8 in significantly higher concentrations [3]. Higher levels of IL-1 have been observed in peri radicular and extra neural tissues in patients with herniated nucleus pulpous (NP) as compared to control [4]. Increased levels of IL-1-beta, macrophages and other inflammatory cells have been observed in disc tissue of herniated NP patients compared to controls. However, results were variable [5]. Inflammatory cells (macrophages, T-lymphocytes), fibroblasts and endothelial cells expressing the Chemokines MCP-1 and macrophage inflammatory protein-1-alpha (MIP1a) were found to be higher in herniated NP group than control group disc samples [6].

In an in vitro study of eight intervertebral disc specimens harvested during spinal surgery for lumbar disc herniation, endogenous IL-1-beta was found to increase mRNA expression of IL-1-beta and IL-6 [7]. In culture media, discs that were herniated spontaneously produced higher levels of matrix Metalloproteinases, nitric oxide, IL-6, and PGE2. Interestingly, TNF-alpha, IL-1beta, IL-1alpha were not found in herniated NP or control discs [8]. PGE2 activity was higher in certain types of disc herniations, and tended to be correlated with clinical findings such as the straight leg raise test [9].

All of these studies quantified or detected the presence of only one or a few cytokines in each subject. Furthermore, the in vitro environment may not provide an accurate representation of the physiologic or pathophysiologic biochemical mileu. Therefore in the current study the concentration of 27 inflammatory cytokines or immune mediators have been measured in whole lumbar intervertebral discs harvested during discectomy surgery, as well as in vivo disc lavages from some of these same discs. The concentrations of these analytics were also compared to that of non-painful control discs.

\section{Methods}

This was a prospectively designed study that received institutional review board approval and enrolled patients undergoing surgical treatment at Sutter Memorial Hospital in Sacramento, California for lumbar degenerative disc disease causing low back pain with or without leg pain. Whole discs were excised in the usual manner during an anterior approach prior to lumbar interbody fusion (ALIF) that was performed as part of a circumferential anterior/posterior lumbar discectomy and fusion at the L3-4, L4-5 or L5-S1 level. The samples were placed into freeze-safe tubes containing $5 \mathrm{ml}$ of protease inhibitor cocktail per tube at a dilution of 1 complete protease inhibitor cocktail tablet (Roche, New York, NY) in $2 \mathrm{ml}$ of phosphatebuffered saline and immediately flash-frozen in liquid nitrogen and stored at -80C until shipping at a later date.

For disc lavage samples, smaller $2 \mathrm{ml}$ tubes were used, containing $0.13 \mathrm{ml}$ volume of protease inhibitor cocktail. Samples were shipped frozen on dry ice to Stanford University School of Medicine for further storage at $-80 \mathrm{C}$, processing and analysis. The investigators at Stanford received the samples labeled with a numerical code and were therefore blinded as to the type of disc material being analyzed until the end of the study. Each patient that agreed to participate in the study was asked to read and sign a consent form and complete the SF-36, Oswestry Disability Index and 11-point visual analog score questionnaires at baseline. Patients were followed post-operatively as usual at 2 weeks, 3 months, 6 months, 12 months and 24 months.

\section{Cytokine concentration assay}

Thirty-one lumbar intervertebral discs from 27 subjects with low back pain with or without leg pain were removed using an anterior discectomy approach. Lavage of the disc was also performed in 19 discs during discectomy for comparative analysis to whole disc samples. For cytokine analysis each excised disc that was frozen in protease inhibitor solution was thawed on ice and the lavasate that had bathed the disc fragments was then analyzed for 27 cytokines simultaneously in each sample using a multiplex immunofluorescent assay system. Lava sates from intradiscal lavages were analyzed in the same manner. Cytokine data were also compared to data from 20 nonpainful lumbar disc samples - 4 from the non-painful control level during discography and 16 from intraoperative lavage of non-painful scoliosis discs.

A pre-configured Bio-Plex ${ }^{\mathrm{TM}}$ Human Cytokine 27-Plex Assay was used to determine the concentration of interleukin-1 $\beta$ (IL$1 \beta \pm$ ), IL-1ra, IL-2, IL-4, IL-5, IL-6, IL-7, IL-8, IL-9, IL-10, IL-12 (p70), IL-13, IL-15, IL-17, granulocyte-colony stimulating factor (G-CSF), granulocyte macrophage-colony stimulating factor (GMCSF), interferon (IFN) $-\gamma$, monocyte chemo attractant protein (MCP)-1, macrophage inflammatory protein(MIP)-1beta (MIP$1 \beta)$, MIP-1a,tumor necrosis factor (TNF)- $\propto$, eotaxin, interferongamma-induced protein-10 (IP-10), fibroblast growth factor (FGF)-basic, RANTES, vascular endothelial growth factor (VEGF) and platelet-derived growth factor (PDGF)-bb. The immunoassay consists of a capture sandwich assay whereby $5.5 \mu \mathrm{m}$ diameter polystyrene beads serve as the solid phase. 


\section{Orthopedics and Rheumatology Open Access Journal}

A monoclonal antibody directed against each cytokine is covalently coupled to the fluorescently-dyed beads. The conjugated beads are then reacted with the sample (or a standard containing a known amount of each targeted cytokine for calibration and as positive control). Then a biotinylated antibody that is specific for the cytokine of interest is added to the reaction, resulting in the formation of a sandwich of antibodies around the targeted cytokine. The reaction is then detected by the addition of streptavidin-phycoerythrin, which binds to the biotinylated detection antibodies [10]. The reaction mixture is then analyzed by the Bio-Plex ${ }^{\mathrm{TM}}$ array reader, which uses a red classification and a green reporter laser to illuminate individual beads to identify each bead's spectrum and associated reporter signal.

The sample size was chosen using a statistical power analysis. The effect size was calculated using estimates of expected mean differences and standard deviations based upon prior studies reported in the literature. Hulse et al. [10] measured a variety of inflammatory cytokines in the serum of rats and reported concentrations ranging from $30 \mathrm{pg} / \mathrm{ml}$ to $1346 \mathrm{pg} / \mathrm{ml}$ with standard deviations ranging from 12 to $26 \%$ of their reported mean values. Prabhakar et. al. [11] measured TNF- $\alpha$, IL-8, IL-6 and IL-1 $\beta$ levels in human plasma and reported a range of 1 to $50 \mathrm{pg} / \mathrm{ml}$ with standard deviations ranging from 13 to $36 \%$ of mean values.

Wu et. al. [12] reported levels of TNF- $\alpha$, IL-1 $\beta$, IL-6, IL-8 and IL-1RA in the range of 2 to $250 \mathrm{pg} / \mathrm{ml}$ in human venous blood with standard deviations in the range of 20 to $30 \%$ of mean values. We therefore chose the high value of $36 \%$ of mean as a conservative estimate of standard deviation expected in our study. De Jageret. al. [13] reported 5-fold higher concentrations IL-10 in control patients as compared to those with Rheumatoid arthritis, while $\mathrm{Wu}$ et. al. [12] reported increases ranging from 4.5- to 10-fold when IL-6, IL-8 and IL-1RA were measured in venous blood before and at the end of an invasive surgical procedure. Therefore, an estimated 2-fold increase or decrease in mean cytokine values was used in our effect size calculation, which is reasonable while maintaining adequate sensitivity.

\section{Exclusion criteria}

Patients who had systemic inflammatory arthritis or had had a lumbar epidural steroid injection during the previous 3 weeks were excluded from all groups.

\section{Results}

The patient population is summarized in (Table 1). Briefly, 31 discs were analyzed from 27 patients, mostly from the L4-5 or L5-S1 levels. Intra-operative disc lavages were also performed in 19 of these patients. Average follow-up of 40 months was achieved (range 12-60 months). In whole discs there was a statistically significant $(\mathrm{p}<0.05)$ elevation of the concentration $(\mathrm{pg} / \mathrm{ml}$; mean +/1 SEM) of IL-13 (1.6+/-0), IL-10 (2.6+/-0), IL- $9(7+/-1)$, MIP-1beta $(9+/-2)$ (Figure 1), FGF-basic (55+/$9)$, eotaxin $(69+/-10)$ (Figure 2), VEGF $(2542+/-255)$ and IP$10(5076+/-607)$ (Figure 3) compared to non-painful control discs. There was also a significantly greater concentration in lavage samples of IL-10, IL-12, IL-9, MIP-1b and VEGF compared to non-painful control discs. RANTES $(3644+/-2251)$ and IL1ra (232 +/- 63) were also detected at high levels in both whole disc and lavage samples but the differences between the nonpainful control levels did not reach statistical significance due to large variation.

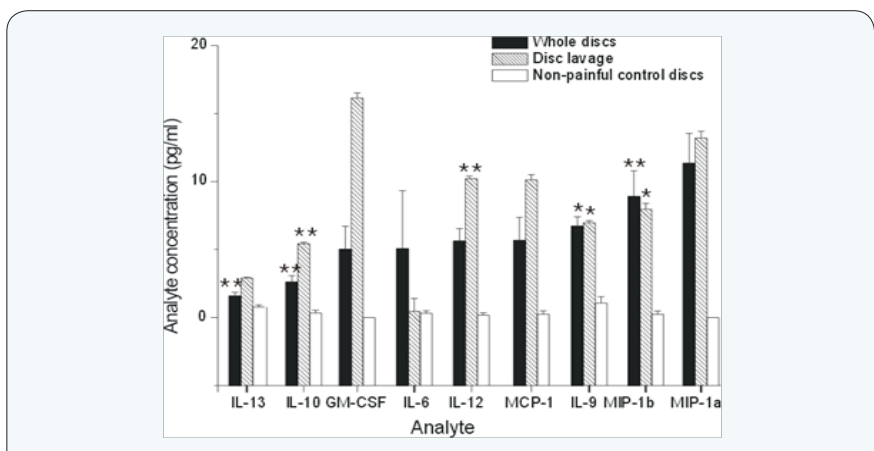

Figure 1: Concentration (picograms/milliliter) of various analytes measured in whole discs (black bars), within disc lavages (thatched bars) and within non-painful control discs (white bars). Error bars are SEM. ${ }^{*} p<0.05 ;{ }^{* *} p<0.01$.
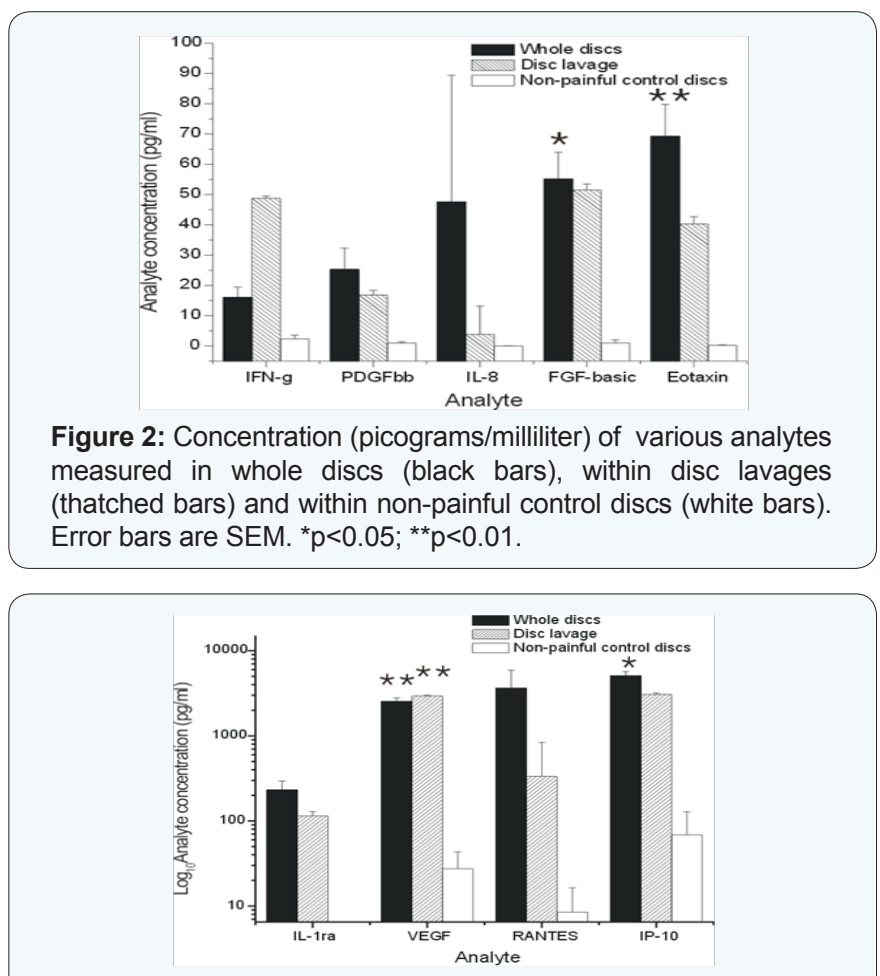

Figure 3: Concentration (picograms/milliliter) of various analytes measured in whole discs (black bars), within disc lavages (thatched bars) and within non-painful control discs (white bars). Error bars are SEM. ${ }^{*} p<0.05 ;{ }^{* *} p<0.01$. 


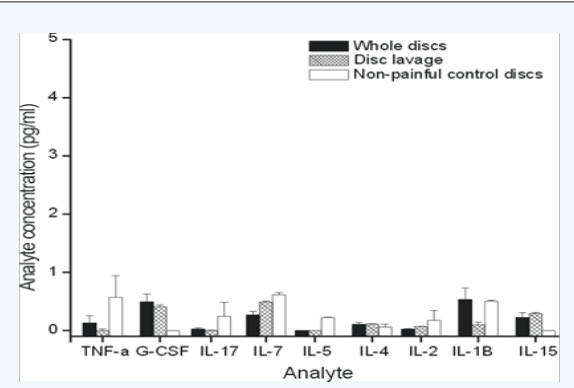

Figure 4: Concentration (picograms/milliliter) of various analytes measured in whole discs (black bars), within disc lavages (thatched bars) and within non-painful control discs (white bars). Error bars are SEM. ${ }^{*} p<0.05 ;{ }^{* *} p<0.01$.

Table 1: Study Population.

\begin{tabular}{|c|c|}
\hline \multicolumn{2}{|c|}{ Study Population } \\
\hline Females & 12 \\
\hline Males & 15 \\
\hline Age-mean \pm SD & $50 \pm 11$ \\
\hline Age-range & $37-68$ \\
\hline Pre-op VAS & $8.5 \pm 1.3$ \\
\hline VAS at $6 \mathrm{mo} F / \mathrm{U}$ & $5.3 \pm 1.9$ \\
\hline VAS at $12 \mathrm{mo} F / U$ & $5.3 \pm 2.5$ \\
\hline VAS at $24 \mathrm{mo} F / U$ & $5.5 \pm 1.5$ \\
\hline $\begin{array}{c}\text { Pre-op SF-36 } \\
(0-100 ; 100 \text { is best })\end{array}$ & $33 \pm 27$ \\
\hline $\begin{array}{c}\text { Pre-op ODI } \\
(0-100 ; 100 \text { is worst) }\end{array}$ & $57 \pm 20$ \\
\hline Whole discs analyzed: & 31 \\
\hline Total & 1 \\
\hline L2-3 & 3 \\
\hline L3-4 & 13 \\
\hline L4-5 & 14 \\
\hline L5-S1 & \\
\hline Intra-op discs lavaged & \\
\hline Total & (1) \\
\hline L3-4 & 2 \\
\hline L4-5 & 7 \\
\hline L5-S1 & 10 \\
\hline
\end{tabular}

The following cytokines were measured at an average concentration of less than $1.0 \mathrm{pg} / \mathrm{ml}$ : IL-15, IL-1beta, IL-2, IL-4, IL-5, IL-7, G-CSF and TNF-a (Figure 4). There was no statistically significant difference in the concentration of cytokines measured by whole disc lavage compared to disc space lavage except for IL-10 ( $p<0.001)$, GM-CSF $(p<0.05)$ and IL-12 $(p<0.005)$; the levels of which were greater in the samples taken from the disc space lavage than from the whole disc. Cytokine concentrations measured in control disc were zero for all measured cytokines except IL-17 $(5.5+/-7.9 \mathrm{pg} / \mathrm{ml})$ and IP-10 (69+/- 59). No significant correlation was found between pre-op VAS or preop ODI and any analytic. There was a significant correlation between pre-op SF-36 and IP-10 ( $\mathrm{p}<0.001 ;$ Rho= .75) and IL-9 (p $<0.05$; Rho=0.61). Weak to moderate correlation was found for 6-month VAS and MCP-1 (Rho = -.48), IL-6 (Rho =0.59), RANTES $($ Rho $=.59)$ and PDGF-bb (Rho $=0.67)$. Statistically significant but weak-moderate correlations were found between change in VAS from pre-op to last follow-up for MCP-1 ( $<<0.05$; Rho=0.47) and VAS at last follow-up for MCP-1 (Rho $=0.60 ; \mathrm{p}<0.005)$ and GM-CSF (Rho=0.47; p<0.05) [13].

\section{Discussion}

Degenerative disc disease of the spine is a common clinical entity. The mechanisms by which it occurs, and how it produces pain, remain unknown. The possibility of a degenerative disc serving as the primary source of back pain remains controversial. However, there is substantial evidence that the intervertebral disc is innervated [14-22] and that there is pathologic ingrowth of nociceptive neuronal fibers at some point during the degenerative process [23,24]. Neuronal sensitization may explain discogenic pain; it is well-established that nociceptive neurons can become sensitized by tissue injury [25], irritant chemicals [26], inflammatory mediators [27], acidic environment [28] and hypoxia [29] - factors that may be present within the degenerative disc [30].

While the pathologic changes that occur in the degenerative disc remain to be investigated, even less is known regarding the bioactive signal that initiates the alteration in intradiscal neuronalfunction. There is some evidence that nerve growth factor (NGF) is up-regulated in the setting of tissue injury and may up-regulate and augment the receptor to which it has greatest affinity - topomyosin-receptor-kinase-A (Trk A). Human annular tissue produces NGF and contains Trk A [31], and NGF and Trk $A$ are increased in discs that were painful during discography compared to those that were not [32]. Inflammatory cytokines in degenerative discs can induce the up-regulation of neurotrophic factors such as NGF [33] and brain-derived neurotrophic factor (BDNF), representing another potential signal.

Inflammatory cytokines or extracellular matrix breakdown products of disc degeneration have previously been detected in the human epidural space $[34,35]$, within the disc during provocative discography [36,37] and within painful vertebral compression fractures [38] and may have potential predictive value for therapeutic intervention $[39,40]$. There is also abundant evidence that herniated nucleus pulpous (NP) causes an inflammatory reaction. NP applied to nerve roots of porcine Cauda equina causes epidural accumulation of leukocytes and mast cells, and minor axonal and schwann cell changes within 3 hrs after application [41]. NP placed around a lumbar nerve root can cause a drop in nerve conduction velocity that is attenuated by the COX-2 -selective NSAID diclofenac [42]. 


\section{Orthopedics and Rheumatology Open Access Journal}

Furthermore, NP applied to the rat dorsal root ganglion in vivo in the absence of mechanical compression can cause a rapid rise in several inflammatory cytokines [43] and can induce a central sensitization detected at the spinal cord level $[44,45]$.

In the present study several immune-modulatory mediators were detected at relatively greater levels in painful degenerative discs compared to control discs - the interleukins IL-13, IL10 and IL-9, chemo tactic chemo kines MIP-1beta (CCL-4) and eotaxin (CCL) and IP-10 (CXC-L-10), and growth factors FGFbasic and VEGF.

IL-13 and IL-10 may be "anti-inflammatory", in that they act in a negative feedback manner to control the pro-inflammatory Cytokine response [46].. IL-13 may act to suppress the production of inflammatory mediators IL-1b, TNF-a and IL-6 from recruited macrophages, lymphocytes and neutrophils, and there is evidence for IL-10 that this is mediated via suppression of the NF-kB-caspase-3 pathway [46]. Conversely, IL-9 is a cytokine produced by T-helper type 2 (Th2) cells and is considered "proinflammatory", inducing proliferation of Th2-lymphocytes [47] and mast cells [48], and has previously been shown to be present in symptomatic vertebral compression fractures [38]. IL-9 is normally undetectable in the serum of healthy volunteers [49], so the average of $7.0 \mathrm{pg} / \mathrm{ml}$ measured within the disc of the current study may represent a small increase in the local environment compared to normal serum levels. In the current study we measured an average IL-13 and IL-10 level of 1.6 and 2.6pg/ $\mathrm{ml}$, respectively. IL-10 and IL-13 are normally undetectable or relatively low in the serum or plasma of healthy volunteers [5052]. The small but statistically significant elevation we observed for these cytokines is unlikely to be clinically significant.

MIP-1beta, also known as CCL-4, is a chemokine that is produced by immune cells such as macrophages, T- and B-lymphocytes, neutrophils, dendritic and natural killer cells in response to pro-inflammatory stimuli including cytokines TNF-a, IL-1B and IFNg [53]. MIP-1beta and its family members orchestrate the acute and inflammatory response by recruiting other proinflammatory cells and are crucial for T-cell chemo taxis and transendothelial migration of monocytes, NK and dendritic cells. MIP-1 cytokines have been shown to play a role in many systemic inflammatory diseases and it's synthesis can be suppressed by the anti-inflammatory cytokine IL-10 [53].

Eotaxin (CCL-11) has eosinophil chemo attractant properties and has been implicated in certain inflammatory conditions such as inflammatory bowel disease and asthma [54]. In the present study it was measured at $69+/-10 \mathrm{pg} / \mathrm{ml}$ in painful discs, but was undetectable in control discs. Eotaxin has been previously measured at levels of $65-104 \mathrm{pg} / \mathrm{ml}$ in the serum of normal subjects [52,55]. Interferon gamma-induced protein (IP-10 aka CXCL-10) is secreted by fibroblasts, monocytes and endothelial cells in response to IFNg and acts as a chemo tactic agent for monocytes/macrophages, NK cells, T-cells and dendritic cells
[56] and may inhibit angiogenesis [57]. IP-10 was detected at high levels $(5076+/-607 \mathrm{pg} / \mathrm{ml})$ in discs of back pain patients in the present study and has been measured at much lower levels (278-355 pg/) $\mathrm{ml}$ in the serum from normal patients [52,55].

FGF-2 (aka FGF-basic) is endogenously produced in cartilage and remains bound to the extracellular matrix until injury, at which time it is released and activates the ERK signaling pathway [58]. The specific functional role of FGF-2 in disc homeostasis is controversial but it has been hypothesized to act as a catabolic mediator, stimulating MMP-13 expression and leading to disc degeneration by the suppression of proteoglycan synthesis [58]. FGF-2 was measured at greater levels from discs of back pain patients in the present study $(55+/-9 \mathrm{pg} / \mathrm{ml})$, compared to undetectable levels in control discs and $7.7 \mathrm{pg} / \mathrm{ml}$ in plasma of normal volunteers [51].

VEGF has been shown to promote both angiogenesis and neurogenesis [59], and its up-regulation has been observed within the DRG following NP exposure [60]. Revascularization and neuronal in-growth are well-known pathophysiologic characteristics of degenerative disc disease, and it has therefore been hypothesized that VEGF is an important mediator of the degenerative process [61]. While VEGF is minimally detectable in the plasma of healthy volunteers $(3.7 \mathrm{pg} / \mathrm{ml})$ [51] or control discs in the present study, we measured high levels $(2542+$ $255 \mathrm{pg} / \mathrm{ml}$ ) within discs from back pain patients.

Several cytokines in the present study were measured at significantly greater levels within discs from back pain patients compared to controls, but at concentrations similar to those reported in prior studies within the serum or plasma. While the significance of this is difficult to determine, the plasma or serum concentration may be irrelevant because the nuclear region of the disc is relatively a vascular.

It is important to note that cytokine concentration measurements are more relative than quantitatively absolute in nature, enabling the comparison of cytokines between and within patients. Although the overall reliability and reproducibility are good to excellent, concentrations may vary between proprietary assay panels [55]. Relatively similar results were obtained for sampling the intra-discal compartment by percutaneousdiscography compared to open operative tissue extraction for most cytokines measured, which may be important information for the design of future studies.

\section{Conclusion}

In conclusion, out of the 27 inflammatory cytokines and chemokines measured using the multiplex panel, 19 were detectable at significant concentrations in the disc and disc space of subjects with degenerative disc disease with low back pain with or without leg pain undergoing surgical treatment with anterior/posterior lumbar discectomy and fusion. The cytokines detected at the greatest concentrations were IP-10, RANTES, 


\section{Orthopedics and Rheumatology Open Access Journal}

and VEGF, IL-1ra, eotaxin and FGF-basic. Compared to control discs, painful degenerative discs demonstrated significantly greater levels of IP-10, VEGF, IL-1ra, eotaxin and FGF-basic. Further studies will be needed to investigate their potential role in degenerative disc disease and as potential clinical biomarkers.

\section{References}

1. Kuslich SD, Ulstrom CL, Michael CJ (1991) The tissue origin of low back pain and sciatica: a report of pain response to tissue stimulation during operations on the lumbar spine using local anesthesia. Orthop clin North Am 22(2): 181-187.

2. Ahn SH, Cho YW, Ahn MW, et al. (2002) mRNA expression of cytokines and chemokines in herniated lumbar intervertebral discs. Spine 27(9): 911-917.

3. Burke JG, Watson RW, McCormack D, et al. (2002) Intervertebral discs which cause low back pain secrete high levels of proinflammatory mediators. J Bone Joint Surg Br 84(2): 196-201.

4. Cooper RG, Freemont AJ, Hoyland JA, et al. (1995) Herniated intervertebral disc-associated periradicular fibrosis and vascular abnormalities occur without inflammatory cell infiltration. Spine 20(5): 591-598.

5. Gronblad M, Virri J, Tolonen J, et al. (1994) A controlled immunohistochemical study of inflammatory cells in disc herniation tissue. Spine 19(24): 2744-2751.

6. Haro H, Shinomiya K, Komori H, et al. (1996) Upregulated expression of chemokines in herniated nucleus pulposus resorption. Spine 21(14): 1647-1652.

7. Jimbo K, Park JS, Yokosuka K, et al. (2005) Positive feedback loop of interleukin-1beta up regulating production of inflammatory mediators in human intervertebral disc cells in vitro. J neurosurg Spine 2(5): 589595

8. Kang JD, Georgescu HI, McIntyre-Larkin L, et al. (1996) Herniated lumbar intervertebral discs spontaneously produce matrix metalloproteinases, nitric oxide, interleukin-6, and prostaglandin E2. Spine 21(3):271-277.

9. O’Donnell JL, O’Donnell AL (1996) Prostaglandin E2 content in herniated lumbar disc disease. Spine 21(14): 1653-16555.

10. Hulse RE, Kunkler PE, Fedynyshyn JP, Kraig RP (2004) Optimization of multiplexed bead-based cytokine immunoassays for rat serum and brain tissue. J neurosci methods 136(1): 87-98.

11. Prabhakar U, Eirikis E, Davis HM (2002) Simultaneous quantification of proinflammatory cytokines in human plasma using the Lab MAP assay. J Immunol Methods 260: 207-218.

12. Wu CT, Jao SW, Borel CO, et al. (2004) The effect of epidural clonidine on perioperative cytokine response, postoperative pain, and bowel function in patients undergoing colorectal surgery. Anesth Analg 99(2): 502-509.

13. de Jager W, te Velthuis H, Prakken BJ, et al. (2003) Simultaneous detection of 15 human cytokines in a single sample of stimulated peripheral blood mononuclear cells. Clin Diagn lab immunol 10(1): 133-139.

14. Bogduk N (1983) The innervation of the lumbar spine. Spine (Phila Pa 1976) 8(3): 286-293.

15. Malinsky J (1959) The ontogenetic development of nerve terminations in the intervertebral discs of man. (Histology of intervertebral discs, 11th communication). Acta anatomica 38: 96-113.

16. Hirsch C, Ingelmark BE, Miller M (1963) The anatomical basis for low back pain. Studies on the presence of sensory nerve endings in ligamentous, capsular and intervertebral disc structures in the human lumbar spine. Acta orthopaedica Scandinavica 33: 1-17.

17. Jackson HC, 2nd, Winkelmann RK, Bickel WH (1966) Nerve endings in the human lumbar spinal column and related structures. J bone joint surg Am 48(7): 1272-1281.

18. Palmgren T, Gronblad M, Virri J, et al. (1999) An immunohistochemical study of nerve structures in the anulus fibrosus of human normal lumbar intervertebral discs. Spine (Phila Pa 1976) 24(20): 2075-2079.

19. KorkalaO,Gronblad M, LiesiP,KaraharjuE (1985)Immunohistochemical demonstration of nociceptors in the ligamentous structures of the lumbar spine. Spine (Phila Pa 1976)10(2): 156-157.

20. Konttinen YT, Gronblad M, Antti-Poika I, et al. (1990) Neuroimmunohistochemical analysis of peridiscal nociceptive neural elements. Spine (Phila Pa 1976) 15(5): 383-386.

21. Brown MF, Hukkanen MV, McCarthy ID, et al. (1997) Sensory and sympathetic innervation of the vertebral endplate in patients with degenerative disc disease. J Bone Joint Surg Br 79(1): 147-153.

22. Fagan A, Moore R, Vernon Roberts B, et al. (2003) ISSLS prize winner: The innervation of the intervertebral disc: a quantitative analysis. Spine 28(23): 2570-2576.

23. Freemont AJ, Peacock TE, Goupille P, et al. (1997) Nerve ingrowth into diseased intervertebral disc in chronic back pain. Lancet 350: 178-181.

24. Palmgren T, Gronblad M, Virri J, et al. (1996) Immunohistochemical demonstration of sensory and autonomic nerve terminals in herniated lumbar disc tissue. Spine (Phila Pa 1976) 21(11): 1301-1306.

25. Reeh PW, Bayer J, Kocher L, et al. (1987) Sensitization of nociceptive cutaneous nerve fibers from the rat's tail by noxious mechanical stimulation. Experimental brain research. 65(3): 505-512.

26. Merrill AW, Cuellar JM, Judd JH, et al. (2008) Effects of TRPA1 agonists mustard oil and cinnamaldehyde on lumbar spinal wide-dynamic range neuronal responses to innocuous and noxious cutaneous stimuli in rats. J neurophysiology 99(2): 415-425.

27. Davis KD, Meyer RA, Campbell JN (1993) Chemo sensitivity and sensitization of nociceptive afferents that innervate the hairy skin of monkey. Journal of neurophysiology 69(4): 1071-1081.

28. Steen KH, Steen AE, Reeh PW (1995) A dominant role of acid pH in inflammatory excitation and sensitization of nociceptors in rat skin, in vitro. J Neurosci 15: 3982-3989.

29. Sugawara O, Atsuta Y, Iwahara T, et al. (1996) The effects of mechanical compression and hypoxia on nerve root and dorsal root ganglia. An analysis of ectopic firing using an in vitro model. Spine 21(18): 20892094

30. Grunhagen T, Shirazi-Adl A, Fairbank JC, et al. (2011) Intervertebral disk nutrition: a review of factors influencing concentrations of nutrients and metabolites. Orthopedic clinics of North America 42(4): 465-477.

31. Gigante A, Bevilacqua C, Pagnotta A, et al. (2003) Expression of NGF, Trka and p75 in human cartilage. Eur J Histochem 47(4): 339-344.

32. Freemont AJ, Watkins A, Le Maitre C, et al. (2002) Nerve growth factor expression and innervation of the painful intervertebral disc. J pathol 197: 286-292.

33. Abe Y, Akeda K, An HS, et al. (2007) Proinflammatory cytokines stimulate the expression of nerve growth factor by human intervertebral disc cells. Spine (Phila Pa 1976) 32(6): 635-642.

34. Scuderi GJ, Cuellar JM, Cuellar VG, et al. (2009) Epidural interferon gamma-immunoreactivity: a biomarker for lumbar nerve root irritation. Spine (Phila Pa 1976) 34(21): 2311-2317. 


\section{Orthopedics and Rheumatology Open Access Journal}

35. Scuderi GJ, Woolf N, Dent K, et al. (2010) Identification of a complex between fibronectin and aggrecan G3 domain in synovial fluid of patients with painful meniscal pathology. Clin biochem 43: 808-814.

36. Cuellar JM, Golish SR, Leroux EJ, et al. (2013) Does a Fibronectin and Aggrecan Complex Play a Role in Painful Vertebral Disks? Pm R 2013 5(4): 297-302.

37. Cuellar JM, Golish SR, Reuter MW, et al. (2010) Cytokine evaluation in individuals with low back pain using discographic lavage. Spine J 10(3): 212-218.

38. Golish SR, Hanna LS, Cuellar JM, et al. (2011) Are persistently symptomatic vertebral compression fractures associated with abnormal inflammatory profiles? A prospective study. J spinal disord tech 24(2): 121-125.

39. Golish SR, Hanna LS, Bowser RP, et al. (2011) Outcome of lumbar epidural steroid injection is predicted by assay of a complex of fibronectin and aggrecan from epidural lavage. Spine (Phila Pa 1976) 36(18): 1464-1469.

40. Smith MW, Ith A, Carragee EJ, et al. (2013) Does the presence of the fibronectin-aggrecan complex predict outcomes from lumbar discectomy for disc herniation? Spine J 2013.

41. Byröd G, Rydevik B, Nordborg C, Olmarker K(1998) Early effects of nucleus pulposus application on spinal nerve root morphology and function. Eur Spine J 7(6): 445-449.

42. Cornefjord M, Olmarker K, Otani K, Rydevik B (2002) Nucleus pulposusinduced nerve root injury: effects of diclofenac and ketoprofen. Eur Spine J 11: 57-61.

43. Cuellar JM, Borges PM, Cuellar VG, et al. (2013) Cytokine expression in the epidural space: a model of noncompressive disc herniationinduced inflammation. Spine (Phila Pa 1976) 38: 17-23.

44. Cuellar JM, Montesano PX, Antognini JF, Carstens E (2005) Application of nucleus pulposus to L5 dorsal root ganglion in rats enhances nociceptive dorsal horn neuronal windup. J neurophysiol 94(1): 35-48.

45. Cuellar JM, Montesano PX, Carstens E (2004) Role of TNF-alpha in sensitization of nociceptive dorsal horn neurons induced by application of nucleus pulposus to L5 dorsal root ganglion in rats. Pain 110(3): 578-587.

46. Vidal PM, Lemmens E, Dooley D, et al. (2013) The role of "antiinflammatory" cytokines in axon regeneration. Cytokine growth factor reviews 24(1): 1-12.

47. Uyttenhove C, Simpson RJ, Van Snick J (1988) Functional and structural characterization of P40, a mouse glycoprotein with T-cell growth factor activity. Proc Natl Acad Sci U S A 85(18): 6934-6938.

48. Matsuzawa S, Sakashita K, Kinoshita T, et al. (2003) IL-9 enhances the growth of human mast cell progenitors under stimulation with stem cell factor. J Immunol 170(7): 3461-3467.
49. Chen N, Lv X, Li P, et al. (2014) Role of high expression of IL-9 in prognosis of CLL. Int j clin exp pathol 7(2): 716-721.

50. Kaskas NM, Moore-Medlin T, McClure GB, et al. (2014) Serum biomarkers in head and neck squamous cell cancer. JAMA otolaryngolhead \& neck surgery 140: 5-11.

51. Crucian B, Stowe R, Mehta S, et al. (2013) Immune system dysregulation occurs during short duration spaceflight on board the space shuttle. J clin immunol 33(2): 456-465.

52. Coburn LA, Horst SN, Chaturvedi R, et al. (2013) High-throughput multi-analyte Luminex profiling implicates eotaxin-1 in ulcerative colitis. PloS one 8(12): e82300.

53. Maurer M, von Stebut E (2004) Macrophage inflammatory protein-1. The international journal of biochemistry \& cell biology 36: 1882-6.

54. Garcia-Zepeda EA, Rothenberg ME, Ownbey RT, et al. (1996) Human eotaxin is a specific chemoattractant for eosinophil cells and provides a new mechanism to explain tissue eosinophilia. Nat med 2(4): 449456.

55. Agalliu I, Xue X, Cushman M, et al. (2013) Detectability and reproducibility of plasma levels of chemokines and soluble receptors. Results in immunology 3: 79-84.

56. Luster AD, Unkeless JC, Ravetch JV (1985) Gamma-interferon transcriptionally regulates an early-response gene containing homology to platelet proteins. Nature 315(6021): 672-676.

57. Angiolillo AL, Sgadari C, Taub DD, et al. (1995) Human interferoninducible protein 10 is a potent inhibitor of angiogenesis in vivo. J exp med 182: 155-162.

58. Ellman MB, Yan D, Ahmadinia K, et al. (2013) Fibroblast growth factor control of cartilage homeostasis. Journal of cellular biochemistry 114(4): 735-742.

59. Jin K, Zhu Y, Sun Y, et al. (2002) Vascular endothelial growth factor (VEGF) stimulates neurogenesis in vitro and in vivo. Proceedings of the National Academy of Sciences of the United States of America 99(18): 11946-11950.

60. Miyoshi S, Sekiguchi M, Konno S, et al. (2011) Increased expression of vascular endothelial growth factor protein in dorsal root ganglion exposed to nucleus pulposus on the nerve root in rats. Spine (Phila Pa 1976) 36: E1-6.

61. Moon HJ, Yurube T, Lozito TP, et al. (2014) Effects of secreted factors in culture medium of annulus fibrosus cells on microvascular endothelial cells: elucidating the possible pathomechanisms of matrix degradation and nerve in-growth in disc degeneration. Osteoarthritis and cartilage / OARS, Osteoarthritis Research Society 22(2): 344-354.

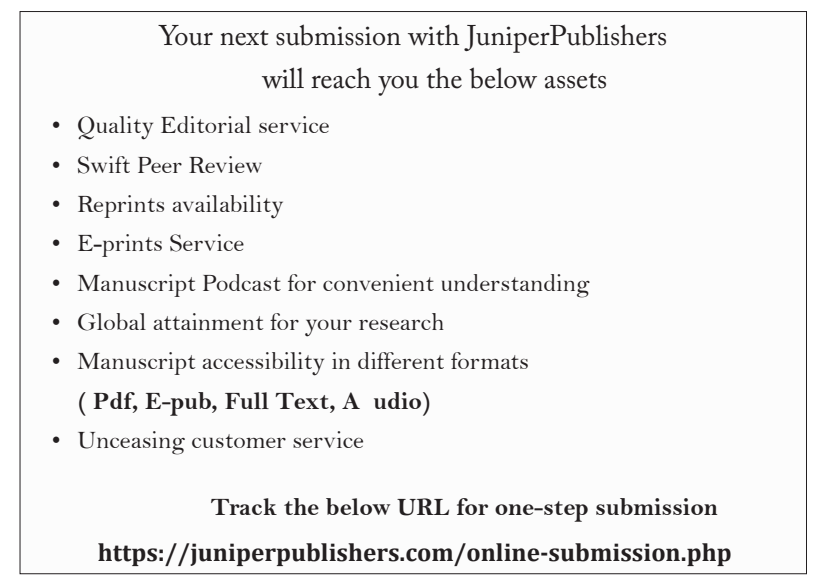

